\title{
Assessment of Acute and Chronic Radiodermatitis of Female Patients with Breast Cancer: The Impact of Radiotherapy and Patient Related Factors
}

\author{
(1) Melis Gönülal' ${ }^{1}$ (1) Zeliha Güzelöz²
}

1University of Health Sciences Turkey, Izmir Tepecik Training and Research Hospital, Clinic of Dermatology, Izmir, Turkey

2University of Health Sciences Turkey, Izmir Tepecik Training and Research Hospital, Clinic of Radiation Oncology, Izmir, Turkey

\section{ABSTRACT}

Background: Radiotherapy used after breast-conserving surgery may cause acute and chronic side effects on skin. In our study, we aimed to investigate skin adverse effects caused by both personal factors and factors about radiotherapy.

Materials and Methods: Female patients with breast cancer aged more than 18 were recruited into this study. Clinical and laboratory data including age, hight, weight, body mass index (BMI), smoking status, educational status, adjuvant chemotherapy and/or hormono therapy, skin phototype, using of any skin care cream, analyze aspartate aminotransferase, alanine aminotransferase, fasting plasma glucose, fasting plasma insulin, homeostatic model assessment-insulin resistance (HOMA-IR) and creatinine, type of surgery, radiotherapy technical details. We examined the area of skin receiving radiotherapy at the end of the first month (early side effects) and the third month (late side effects) of radiotherapy for breast.

Results: We reached 78 patients but 56 of 78 patients came to dermatology outpatient clinic for their second controls and 34 of 78 patients came for their third controls. We determined significant relationships between BMI and acute radiodermatitis $(p=0.021)$. In addition, there were significant relationships between smoking, BMI, fasting plasma insulin, HOMA-IR and chronic radiodermatitis $(p=0.01, p=0.049$, $p=0.012, p=0.025$ respectively).

Conclusion: According to our study, smoking, BMI, fasting plasma insulin, HOMA-IR are significantly effective on radiodermatitis. Nevertheless, further studies conducted with more extensive patient series are needed to validate our findings and assess their clinical importance.

Keywords: Radiodermatitis, Breast cancer, Radiotherapy

\section{Introduction}

Radiotherapy is a treatment method that's used after breastconserving surgery, with this method locoregional recurrence of breast cancer is tried to be prevented [1]. Irradiation of the breast may cause acute and chronic side effects on skin. There are different factors that are effective on skin side effects, such as total delivered dose, dose per fraction, location and volume of the treated area, radiating energy, concomitant chemotherapy [2,3,4,5]. According to the literature individual variations depending on age, chronic diseases, skin phototypes, genetic predisposition, skin damage from the previous are important on occuring early and late skin damages. Skin reactions vary from mild erythema to necrosis [6]. In our study, we aimed to investigate skin adverse effects caused by both personal factors and factors about radiotherapy. 


\section{Materials and Methods}

\section{Study Design}

This study was designed as a prospective single-center study, and it was conducted under the ethical principles reported in the Declaration of Helsinki. It was approved by the University of Health Sciences Turkey, Izmir Tepecik Training and Research Hospital Ethical Review Committee (protocol number: 2019/1331, date: 11.09.2019). Female patients with breast cancer aged more than 18 who presented to the radiation oncology outpatient clinic of Izmir Tepecik Training and Research Hospital between September 2019 and October 2020 were recruited into this study. Dermatologic examinations of patients were always made by the same dermatologist of the same hospital. Both verbal and written informed consents were obtained from study participants. Clinical data including age, hight, weight, body mass index (BMI), smoking status, educational status, adjuvant chemotherapy and/or hormono therapy, skin phototype. All study patients were asked to give blood samples to analyze aspartate aminotransferase, alanine aminotransferase, fasting plasma glucose, fasting plasma insulin, homeostatic model assessment-insulin resistance (HOMA-IR) and creatinine. We examined the area of skin receiving radiotherapy at the end of the first month (early side effects) and the third month (late side effects) of radiotherapy for breast. We used Radiation Therapy Oncology Group/European Organization for Research and Treatment of Cancer radiation toxicity grading system for acute and chronic skin side effects $[7,8]$.

\section{Radiation Therapy}

In our clinic, adjuvant radiotherapy is applied to all patients who underwent breast-conserving surgery and to all patients who underwent mastectomy with T3-4, N (+) in accordance with our hospital protocol. In patients undergoing breast conserving surgery, was applied to the whole breast radiotherapy and then an additional dose (boost) to the tumor bed. In those who undergo mastectomy, radiotherapy was applied to the chest wall. Boost was given to the incision scar in patients with skin involvement and positive surgical margins. In both groups, patients with positive lymph nodes were applied to peripheral lymph nodes irradiation.

A total of 50 Gy was given to the whole breast or chest wall, and boost to the tumor bed or incision scar with 2 Gy fraction dose in 5 days. If the surgical margin is positive or there is skin involvement, the boost dose is increased to $66 \mathrm{~Gy}$.

Eclips version 15.5 is used for all plans by using the field in field technique with two conformal tangential fields has also been done including tomograpy based planning, simulation, verification\&quality assurance. $110 \%$ the maximum dose (Dmax) was allowed in the plans. Two tangential fields are planned with single or combined photon energy and boost is planned by using electron or photon. Treatment was given in the Varian Vital Beam linear accelerator.

In the light of clinical information and planning data, which breast of the patients is irradiated, it's stage according to the "American Joint Committee on Cancer" Cancer Staging Manual 8th Edition, type of surgery, radiotherapy technical details (energy, presence of bolus, mean-Dmax) were recorded.

In their first concultation, patients are advised to take a warm shower and not to use abrasive cleaning products and cosmetic products during the therapy. Patients come to the polyclinic once a week during the treatment process. Epithelizing cream is recommended to patients about two weeks when acute side effects begin. Additional medication is recommended if increased side effects are observed.

\section{Statistical Analysis}

Statistical power analysis was made with G-Power 3.1.9.4 programme and we determined that our study had 85.8\% power. Statistical analysis was performed with Statistical Package for the Social Sciences version 17.0 statistic software package. Different variables were investigated with analytical methods if they were suitable for normal distribution (Kolmogorov-Smirnov/Shapiro-Wilk tests). In descriptive analysis, parameters were written as frecuency, percent, mean, standard deviation. Chi-squared test and Spearman test were used in comparing categorical data. $P$ values of less than 0.05 were regarded as statistically significant.

\section{Results}

We reached 78 patients but 56 of 78 patients came to dermatology outpatient clinic for their second controls and 34 of 78 patients came for their third controls. Therefore we recorded the datas of 56 patients, excluded 22 patients who never came to controls because of Coronavirus disease-2019 pandemic. All datas of patients were presented in tables (Tables 1, 2, 3, 4, 5). None of the patients stopped treatment due to the side effects. The mean radiotherapy dose (Dmean) was 55.45 \pm 4.37 Gy (minimum 50, maximum 62) and the Dmax was 62.04 \pm 4.33 Gy (minimum 53, maximum 74). When we investigate only the patients who came to their third dermatology controls, we determined that Dmean was 55.97 $\pm 4.68 \mathrm{~Gy}$ (minimum 50, maximum 62) and Dmax was 61.65 \pm 3.96 Gy (minimum 53, maximum 66). We determined significant relationships between BMI and acute radiodermatitis $(p=0.021)$ (Table 6). In addition, there were significant relationships between smoking, BMI, fasting plasma insulin, HOMA-IR and chronic radiodermatitis $(p=0.01$, $p=0.049, p=0.012, p=0.025$ respectively) (Tables 5,6$)$. There were no correlations between features about radiotherapy and acute and chronic radiodermatitis (Table 7). 


\section{Discussion}

The most common adverse effect of breast cancer radiotherapy is radiodermatitis. The pathogenesis of radiodermatitis is complex. A combination of radiation tissue injury occurs after an inflammatory reaction. Vascular permeability and vasodilation increase and consequently an erythematous skin reaction happens and then an inflammatory response occurs. Keratinocytes, fibroblasts, and endothelial cells take part in this inflammatory reaction with the cytokines and chemokines they produce and acute and chronic radiodermatitis can occur as an adverse effect [9].

Table 1. Parameters that may be effective on skin damage during radiotherapy

\begin{tabular}{|c|c|}
\hline Parameters & Patients (n/\%) \\
\hline \multicolumn{2}{|l|}{ Smoking } \\
\hline - Yes & $12 / 21.4$ \\
\hline - No & $44 / 78.6$ \\
\hline \multicolumn{2}{|c|}{ Adjuvant chemotherapy } \\
\hline - Yes & $28 / 50$ \\
\hline$-\mathrm{No}$ & $28 / 50$ \\
\hline \multicolumn{2}{|c|}{ Adjuvant hormono therapy } \\
\hline - Yes & $7 / 12.5$ \\
\hline$-\mathrm{No}$ & $49 / 87.5$ \\
\hline \multicolumn{2}{|l|}{ Educational status } \\
\hline - Illiterate & $8 / 14.3$ \\
\hline - Literate & $2 / 3.6$ \\
\hline - Primary school & $29 / 51.8$ \\
\hline - Middle school & $0 / 0$ \\
\hline - High school & 9/16.1 \\
\hline - University & $8 / 14.3$ \\
\hline \multicolumn{2}{|c|}{ Skin phototype (Fitzpatrick) } \\
\hline-1 & $4 / 7.1$ \\
\hline-2 & $37 / 66.1$ \\
\hline-3 & $14 / 25$ \\
\hline-4 & $1 / 1.8$ \\
\hline \multicolumn{2}{|l|}{ Skin care cream } \\
\hline - Yes & $15 / 26.8$ \\
\hline - No & $41 / 73.2$ \\
\hline \multicolumn{2}{|c|}{ Type of skin care cream } \\
\hline - None & $41 / 73.2$ \\
\hline - Calendula cream & $1 / 1.8$ \\
\hline - Any barrier cream & $2 / 3.6$ \\
\hline - St. John's wort oil & $4 / 7.1$ \\
\hline - Radiocare & $6 / 10.7$ \\
\hline - Urea & $2 / 3.6$ \\
\hline Total & $56 / 100$ \\
\hline
\end{tabular}

The impact of smoking is uncertain. Some researchs found significant relationships between smoking and radiodermatitis [10,11], some studies couldn't find any significant relationships $[12,13,14]$. In contrary to the findings of the studies of Back et al. [12] and Borm et al. [14] our results suggest that smoking is associated with chronic radiodermatitis. We think smoking is a risk factor for chronic radiodermatitis not for acute radiodermatitis.

Age is mentioned in the extrinsic factors of radiodermatitis [11]. According to the study of Back et al. [12] and Borm et al. [14] age isn't effective on occuring of radiodermatitis. We reached the same result in our study therefore we think that age isn't an effective factor of radiodermatitis.

Adjuvant chemotherapy and hormono therapy can be effective factors on occuring of radiodermatitis [11]. According to the study of Iwakawa et al. [11] and Borm et al. [14], it wasn't be found any statistically significant relationship between adjuvant chemotherapy and hormono therapy and radiodermatitis. Our findings are in line with Iwakawa et al. [11] and Borm et al. [14]. We think that adjuvant chemotherapy and hormono therapy aren't effective factors for radiodermatitis.

Skin phototype classifications were initially developed by Fitzpatrick [13]. According to the study of Yamazaki et al. [13], self-reported skin phototype can be potentially a good predictor determining skin sensitivity to radiation exposure during the process of clinical screening. In our study, incompatible with the study of Yamazaki et al. [13], analysis of the relationships between skin phototype and radiodermatitis revealed that radiodermatitis couldn't be associated with skin phototype. Additionally, in the study of Yamazaki et al. [13], researchers found that the "suntan" skin phototype predicted higher pigmentation in radiation dermatitis. We think that skin phototype isn't an effective factor for radiodermatitis.

Non-comedogenic emollient creams are recommended for the care of skin that receives radiotherapy [15]. According to the study of

Table 2. Laboratuary findings of patients with breast cancer

\begin{tabular}{|c|c|}
\hline Parameters (normal range) & $\begin{array}{l}\text { Patients } \\
\text { (mean } \pm \text { standard } \\
\text { deviation) }\end{array}$ \\
\hline Age & $53.02 \pm 12.12$ \\
\hline BMI $\left(18.5-24.9 \mathrm{~kg} / \mathrm{m}^{2}\right)$ & $27.6 \pm 4.84$ \\
\hline AST $(0-35 \mathrm{U} / \mathrm{L})$ & $19.83 \pm 5.62$ \\
\hline ALT (0-35 U/L) & $20.6 \pm 6.54$ \\
\hline Creatinine $(0.6-1.1 \mathrm{mg} / \mathrm{dL})$ & $0.73 \pm 0.1$ \\
\hline Fasting plasma glucose $(74-106 \mathrm{mg} / \mathrm{dL})$ & $108.91 \pm 27.92$ \\
\hline Fasting plasma insulin $(1.9-23 \mathrm{mU} / \mathrm{L})$ & $9.54 \pm 6.29$ \\
\hline HOMA-IR (0-2.5) & $2.66 \pm 2.31$ \\
\hline
\end{tabular}

BMI: Body mass index, AST: Aspartate aminotransferase, ALT: Alanine aminotransferase, HOMA-IR: Homeostatic model assessment-insulin resistance 
Yamazaki et al. [15], daily dermocosmetic use is useful from the beginning of radiotherapy to prevent acute radiodermatitis. In our study, we determined that 15 cases were using any dermatologic care cream (antibacterial creams, creams including zinc-urea, radiocare etc.) in addition of epithelizing cream. Nevertheless, we didn't found any significant relationship between using extra skin care cream and radiodermatitis. If we could include more cases, maybe the results could change in favor of skin care creams. According to another study, Calendula officinalis can prevent radiodermatitis

\begin{tabular}{|c|c|}
\hline Parameters & Patients (n/\%) \\
\hline \multicolumn{2}{|l|}{ Breast } \\
\hline - Right & $23 / 41.1$ \\
\hline - Left & $31 / 55.4$ \\
\hline - Both right and left & $2 / 3.6$ \\
\hline \multicolumn{2}{|l|}{ Type of surgery } \\
\hline$-B C S$ & $43 / 76.8$ \\
\hline - Total mastectomy & $13 / 23.2$ \\
\hline \multicolumn{2}{|l|}{ Pathology } \\
\hline - DCIS & $2 / 3.6$ \\
\hline- IDC & $54 / 96.4$ \\
\hline \multicolumn{2}{|l|}{ Boost } \\
\hline - Yes & $45 / 80.4$ \\
\hline - No & $11 / 19.6$ \\
\hline \multicolumn{2}{|l|}{ Bolus } \\
\hline - Yes & $2 / 3.6$ \\
\hline- No & $54 / 96.4$ \\
\hline \multicolumn{2}{|l|}{ Boost energy type } \\
\hline - Photon & $35 / 62.5$ \\
\hline - Electron & $21 / 37.5$ \\
\hline \multicolumn{2}{|l|}{ Acute damage of skin } \\
\hline - No damage & $2 / 3.6$ \\
\hline - Grade 1 & $15 / 26.8$ \\
\hline - Grade 2 & $14 / 25$ \\
\hline - Grade 3 & $25 / 44.6$ \\
\hline \multicolumn{2}{|c|}{ Chronic damage of skin (for 34 patients) } \\
\hline - No damage & $8 / 14.3$ \\
\hline - Grade 1 & $5 / 8.9$ \\
\hline - Grade 2 & $21 / 37.5$ \\
\hline - Total & $34 / 60.7$ \\
\hline \multicolumn{2}{|c|}{ Energy used on primary area } \\
\hline$-6 m v x$ & $11 / 19.6$ \\
\hline - 6-10 mvx & $4 / 7.1$ \\
\hline$-6-15 m v x$ & $41 / 73.2$ \\
\hline Total & $56 / 100$ \\
\hline \multicolumn{2}{|c|}{$\begin{array}{l}\text { BCS: Breast conserving surgery, DCIS: Ductal carcinoma in situ, IDC: Invasive } \\
\text { ductal carcinoma }\end{array}$} \\
\hline
\end{tabular}

and the studies were not conclusive, either due to systematic driving errors or results without statistical significance [6].

Our investigation regarding the relationship between educational status and radiodermatitis revealed that educational status isn't an

Table 4. Stage of breast cancer of patients according to the American Joint Committee on Cancer stagining system

\begin{tabular}{|l|l|}
\hline Phases & Patients $(\mathbf{n} / \%)$ \\
\hline Stage 0 (TisN0M0) & $2 / 3.6$ \\
\hline Stage 1 & $11 / 19.6$ \\
\hline Stage 2 & $31 / 55.4$ \\
\hline Stage 3 & $9 / 16.2$ \\
\hline Stage 4 & - \\
\hline
\end{tabular}

Table 5. Correlations between personel factors of patients and acute and chronic radiodermatitis

\begin{tabular}{|l|l|l|}
$\mathbf{p}$ & $\begin{array}{l}\text { Acute } \\
\text { radiodermatitis }\end{array}$ & $\begin{array}{l}\text { Chronic } \\
\text { radiodermatitis }\end{array}$ \\
\hline Age & 0.98 & 0.63 \\
\hline Smoking & 0.84 & $0.01^{*}$ \\
\hline Adjuvant chemotherapy & 0.79 & 0.95 \\
\hline Adjuvant hormono therapy & 0.89 & 0.8 \\
\hline Educational status & 0.49 & 0.51 \\
\hline Skin phototype (Fitzpatrick) & 0.22 & 0.65 \\
\hline Using care cream for skin & 0.36 & 0.22 \\
\hline *p $\leq 0.05$ & &
\end{tabular}

Table 6. Correlations between laboratory findings of patients and acute and chronic radiodermatitis

\begin{tabular}{|l|l|l|}
\hline $\mathbf{p}$ & $\begin{array}{l}\text { Acute } \\
\text { radiodermatitis }\end{array}$ & $\begin{array}{l}\text { Chronic } \\
\text { radiodermatitis }\end{array}$ \\
\hline BMI & $0.021^{*}$ & $0.049^{*}$ \\
\hline Fasting plasma glucose & 0.15 & 0.68 \\
\hline Fasting plasma insulin & 0.78 & $0.012^{*}$ \\
\hline HOMA-IR & 0.63 & $0.025^{*}$ \\
\hline $\begin{array}{l}\text { BMI: Body mass index, HOMA-IR: } \\
\text { resistance, * }{ }^{*} \leq 0.05\end{array}$ &
\end{tabular}

Table 7. Correlations between features about radiotherapy and acute and chronic radiodermatitis

\begin{tabular}{|l|l|l|}
$\mathbf{p}$ & $\begin{array}{l}\text { Acute } \\
\text { radiodermatitis }\end{array}$ & $\begin{array}{l}\text { Chronic } \\
\text { radiodermatitis }\end{array}$ \\
\hline Boost & 0.082 & 0.49 \\
\hline Energy type & 0.22 & 0.2 \\
\hline Type of surgery & 0.059 & 0.46 \\
\hline Dmean skin (Gy) & 0.48 & 0.29 \\
\hline Dmax skin (Gy) & 0.36 & 0.26 \\
\hline Energy used on primary area & 0.62 & 0.58 \\
\hline Dmean the matotapy dose & &
\end{tabular}

Dmean: the mean radiotherapy dose, Dmax: the maximum radiotherapy dose, ${ }^{*} \mathrm{p} \leq 0.05$ 
effective factor on occuring acute or chronic radiodermatitis. We didn't found any literature that mentioned relationships between educational status and radiodermatitis.

BMI can be thought an effective factor for occuring radiodermatits. In the study of Yamazaki et al. [15] BMI was found to be a simple and effective tool for examining radiation dermatitis. In our study, compatible with the research of Yamazaki et al. [15], we found that there was a significant relationship between BMI and acute and chronic radiodermatitis. According to our study patients with normal BMI are less likely to have acute and chronic radiodermatitis.

Diabetes mellitus has been cited as one of the causes of radiodermatitis [16]. We determined in our study that there were significant relationships between fasting plasma insulin, HOMA-IR and chronic radiodermatitis. We observed that these two factors weren't effective on acute radiodermatitis. In the literature we didn't find any other studies that were similar to our work about the effects of fasting plasma glucose, fasting plasma insulin and HOMAIR on radiodermatitis.

In our study, we observed that boost, energy type, type of surgery, Dmean, Dmax used on primary area weren't effective on occuring of acute and chronic radiodermatitis. In Borm et al.'s [14] study with 255 cases, researchers investigated acute radiodermatitis in modern adjuvant 3D conformal radiotherapy for breast cancer and used for scoring of radiodermatitis Common Terminology Criteria for Adverse Events V.4.0. The researchers observed that boost wasn't significantly effective on occuring of acute radiodermatitis. In this study, 92.2\% of all cases received boost. In our research, the percentage of cases who got boost was $80.4 \%$. In the same study, researchers didn't find any significant relationships between Dmax and Dmean and radiodermatitis. According to our research, we think parameters about radiotherapy technics weren't significantly effective on acute and chronic radiodermatitis. That is because of using high conformal techniqeu and also close clinical follow up.

\section{Study Limitations}

Our study has some limitations which need to be considered while evaluating its findings. First, it is a single-center study. Second, although radiation oncologist was always working in the same part of hospital, dermatologist was working in the three different parts of the hospital during the process of research, therefore patients who had skin damage because of radiotherapy, couldn't be sometimes examined by dermatologist. Somestimes, cases forgot their second and third visits for dermatology outpatient clinic. If dermatologist and radiation oncologist always worked in the same part of hospital, the number of patients would be higher.

\section{Conclusion}

In conclusion, during breast cancer radiotherapy, nearly all patients will experience radiodermatitis. Different factors can be effective on occuring radiodermatitis. According to our study, smoking, BMI, fasting plasma insulin, HOMA-IR are significantly effective on radiodermatitis. Our study was the first to evaluate the relationship between radiodermatitis and different, numerous factors to the best of our knowledge. Nevertheless, further studies conducted with more extensive patient series are needed to validate our findings and assess their clinical importance.

\section{Ethics}

Ethics Committee Approval: The study were approved by the University of Health Sciences Turkey, Izmir Tepecik Training and Research Hospital Ethical Review Committee (protocol number: 2019/13-31, date: 11.09.2019).

Informed Consent: Both verbal and written informed consents were obtained from study participants.

Peer-review: Internally peer-reviewed.

\section{Authorship Contributions}

Surgical and Medical Practices: M.G., Z.G., Concept: M.G., Z.G., Design: M.G., Z.G., Data Collection or Processing: M.G., Z.G., Analysis or Interpretation: M.G., Z.G., Literature Search: M.G., Z.G., Writing: M.G., Z.G.

Conflict of Interest: No conflict of interest was declared by the authors.

Financial Disclosure: The authors declared that this study received no financial support.

\section{References}

1. Fisher B, Anderson S, Bryant J, Margolese RG, Deutsch M, Fisher ER, Jeong $J \mathrm{H}$, Wolmark N. Twenty-year follow-up of a randomized trial comparing total mastectomy, lumpectomy, and lumpectomy plus irradiation for the treatment of invasive breast cancer. N Engl J Med 2002;347:1233-1241.

2. Fehlauer F, Tribius S, Alberti W, Rades D. Late effects and cosmetic results of conventional versus hypofractionated irradiation in breast-conserving therapy. Strahlenther Onkol 2005;181:625-631.

3. Johansson S, Svensson H, Denekamp J. Dose response and latency for radiation-induced fibrosis, edema, and neuropathy in breast cancer patients. Int J Radiat Oncol Biol Phys 2002;52:1207-1219.

4. Lilla C, Ambrosone CB, Kropp S, Helmbold I, Schmezer P, von Fournier D, Haase W, Sautter-Bihl ML, Wenz F, Chang-Claude J. Predictive factors for late normal tissue complications following radiotherapy for breast cancer. Breast Cancer Res Treat 2007;106:143-150.

5. Bentzen SM, Overgaard J. Patient-to-Patient Variability in the Expression of Radiation-Induced Normal Tissue Injury. Semin Radiat Oncol 1994;4:6880 .

6. Di Franco R, Sammarco E, Calvanese MG, De Natale F, Falivene S, Di Lecce A, Giugliano FM, Murino P, Manzo R, Cappabianca S, Muto P, Ravo V. Preventing the acute skin side effects in patients treated with radiotherapy for breast 
cancer: the use of corneometry in order to evaluate the protective effect of moisturizing creams. Radiat Oncol 2013;8:57.

7. NIH. Common Terminology Criteria for Adverse Events (CTCAE). Publication date: June 14, 2010. Available at: https://ctep.cancer.gov/ protocoldevelopment/electronic_applications/ctc.htm

8. Spałek M. Chronic radiation-induced dermatitis: challenges and solutions. Clin Cosmet Investig Dermatol 2016;9:473-482.

9. Karbasforooshan H, Hosseini S, Elyasi S, Fani Pakdel A, Karimi G. Topical silymarin administration for prevention of acute radiodermatitis in breast cancer patients: A randomized, double-blind, placebo-controlled clinical trial. Phytother Res 2019;33:379-386.

10. Wells M, Macmillan M, Raab G, MacBride S, Bell N, MacKinnon K, MacDougall $\mathrm{H}$, Samuel L, Munro A. Does aqueous or sucralfate cream affect the severity of erythematous radiation skin reactions? A randomised controlled trial. Radiother Oncol 2004;73:153-162

11. Iwakawa M, Noda S, Yamada S, Yamamoto N, Miyazawa Y, Yamazaki H, Kawakami Y, Matsui Y, Tsujii H, Mizoe J, Oda E, Fukunaga Y, Imai T. Analysis of non-genetic risk factors for adverse skin reactions to radiotherapy among 284 breast cancer patients. Breast Cancer 2006;13:300.
12. Back M, Guerrieri M, Wratten C, Steigler A. Impact of radiation therapy on acute toxicity in breast conservation therapy for early breast cancer. Clin Oncol (R Coll Radiol) 2004;16:12-16.

13. Yamazaki H, Yoshida K, Nishimura T, Kobayashi K, Tsubokura T, Kodani N, Aibe $\mathrm{N}$, Nishimura T. Association between skin phototype and radiation dermatitis in patients with breast cancer treated with breast-conserving therapy: suntan reaction could be a good predictor for radiation pigmentation. J Radiat Res 2011;52:496-501.

14. Borm KJ, Loos M, Oechsner M, Mayinger MC, Paepke D, Kiechle MB, Combs SE, Duma MN. Acute radiodermatitis in modern adjuvant 3D conformal radiotherapy for breast cancer - the impact of dose distribution and patient related factors. Radiat Oncol 2018;13:218.

15. Yamazaki H, Yoshida K, Kobayashi K, Tsubokura T, Kodani N, Aibe N, Ikeno H, Nishimura T. Assessment of radiation dermatitis using objective analysis for patients with breast cancer treated with breast-conserving therapy: influence of body weight. Jpn J Radiol 2012;30:486-491.

16. Spasić B, Jovanović M, Golušin Z, Ivanov O,Tešanović D. Radiodermatitis - review of treatment options. Serbian Journal of Dermatology and Venereology 2018;10:71-81. 